\title{
Cooperação horizontal Sul-Sul: arranjos de concertação política entre a Índia, o Brasil e a África do Sul
}

\author{
South-South horizontal cooperation: arrangements for policy \\ consultation between India, Brazil and South Africa
}

DIEGO DE FREITAS RODRIGUES*

Rev. Bras. Polít. Int. 53 (1): 45-66 [2010]

\section{Introdução}

A ideia de concertações Sul-Sul não é recente e muito menos os objetivos que levam a formar-se coalizões entre países do Hemisfério Sul, observandose a necessidade de se pensar nos interesses e nas estratégias desenvolvidas conjuntamente num ambiente internacional interdependente e assimétrico. Este contexto de maior aproximação entre países do Sul pode ser identificado como um tipo de cooperação horizontal, objetivando-se uma concertação com vistas à obstrução das desigualdades internacionais dirigidas pelos países desenvolvidos do Norte, bem como ações conjuntas com vistas ao enfrentamento de problemas domésticos semelhantes.

Segundo Oliveira et al $(2006,489)$ os Estados Intermediários: (i) teriam um interesse comum ou então uma agenda internacional aderente às ideias dos Estados Intermediários ou; (ii) teriam interesses divergentes que se compatibilizariam devido a serem Estados Intermediários. Nesse caso, ainda segundo Oliveira et al $(2006,490)$, essa articulação derivaria de: (i) referências mútuas ao lidar com problemas de caráter semelhante e; (ii) interesses de agenda em fomentar uma maior interdependência como recurso de alargamento das parcerias, retirando-se de um limitado vínculo unilateral com países desenvolvidos.

Política externa trata especialmente de escolher entre oportunidades e demandas "ofertadas" no ambiente doméstico (porque a política externa é uma política pública em nosso entender) e, claro, internacional. Por exemplo, saídas (busca por novos parceiros) "ao Norte" e "ao Sul" são escolhas na formulação de política externa da Índia, do Brasil e da África do Sul. Escolhas no sentido

* Doutorando em Ciência Política pelo Programa de Pós Graduação em Ciência Política da Universidade Federal de São Carlos - UFSCAR (diegofreitas@gmail.com). 
de que as "saídas" (sejam por razões comerciais, de segurança, meio ambiente, energia, etc) configuram, a priori, relevância no projeto interno dominante e, naturalmente, tomam parte na agenda governamental. As escolhas podem indicar uma reorientação de prioridades ou de tratamento preferencial por parte de administrações na forma de melhor conduzir as inserções internacionais dos países. Uma mudança de tratamento pode inferir que uma parceria não fosse mais encarada como estratégica pelos policy makers e sim como cooperativa ou vice-versa.

A percepção de melhores formas de inserção aos países insere-se dentro de um quadro que aponta a seguinte indagação: qual a melhor forma de cooperação para países como a Índia, o Brasil e a Âfrica do Sul? Não existe unanimidade na resposta. Se a melhor "saída" for ao Sul, alguns analistas apontam que países de capacidades materiais semelhantes tem mais razôes para competir no ambiente internacional do que motivos para cooperarem (Viola e Pio, 2003), perspectiva que inviabilizaria um tipo de coalizão endógena-ofensiva, aqui identificada como a caracterizada pela coalizão IBAS. Essa perspectiva tem seu contraponto. Samuel Pinheiro Guimarães (1998) considera que, caso os países intermediários sigam uma orientação de privilégio com os países desenvolvidos do Norte, existiriam chances acentuadas de que não elevariam seus status no ambiente internacional.

A efetividade de uma aproximação entre países intermediários calcando-se a prerrogativa de uma maior cooperação internacional objetivando a contraposição aos interesses e atividades de caráter unilateral dos países desenvolvidos, concertouse em cenários institucionais como a Organização das Nações Unidas (ONU) e a Organização Mundial do Comércio (OMC), buscando, quanto à primeira, uma reforma do Conselho de Segurança da ONU (CSONU), condomínio decisório da instituição; quanto à segunda, uma maior articulação na recém-criada OMC com vistas a obtenção de negociações econômicas mais benéficas aos países do Sul nas inúmeras rodadas de negociação entre os países no seio da instituição.

É importante destacar que as instituições internacionais são tomadas aqui como fatores de incentivo à cooperação, pressupondo que as instituições internacionais promovem meios para a descoberta de interesses comuns por meio de diálogo e reduzindo os custos de negociação (Keohane, 2005). Por exemplo, na esfera econômica, o perfil de credibilidade e estabilidade macroeconômica é perseguido pelos três países e suas políticas externas são orientadas em torno da percepção de que seus países são grandes mercados emergentes. E na esfera política, a busca por valorizar instituições internacionais prestigiando seus colegiados decisórios e, ainda mais, na busca por reformar seus desenhos institucionais demonstra a aderência ainda de um mesmo fio condutor que guiou as políticas dos países desde a década de 1960 no ambiente internacional.

Desta forma, o novo desenho da política internacional tem, nos países do Sul, atores de real importância, e os países em desenvolvimento reconhecem essa nova condição e por ela articulam meios de maior projeção no ambiente internacional. A institucionalização de coalizões Sul-Sul é percebida como um recurso válido e 
estratégico para a melhor forma de inserção dos países no ambiente internacional, algo comparativamente válido tanto no período da Guerra Fria quanto hoje em dia. Embora exista um legado institucional no teor das concertações entre países em desenvolvimento, o desempenho político das coalizóes diferencia-se de um momento para outro, seja pelas mudanças estruturais no ambiente internacional, seja pelos novos arranjos das concertações Sul-Sul pós Guerra Fria.

O desempenho político eficiente de uma concertação política entre a Índia, o Brasil e a África do Sul depende de políticas externas assertivas e alinhadas na busca por atingir suas respectivas metas institucionais, dimensionadas aqui para avaliação em instituições internacionais como a ONU e a OMC. Portanto, a observação de elementos de alinhamento entre as políticas externas da Índia, do Brasil e da África do Sul está diretamente dependente de como e em torno de que as políticas externas dos países concertados são orientadas.

\section{Multilateralismo Sul-Sul: uma "saída" viável para enfrentar aos constrangimentos sistêmicos?}

A articulação entre novos centros de poder com capacidade de influir e decidir conjuntamente os rumos do ambiente econômico e político internacional foi, acentuadamente, galgando relevância não apenas nas relações bilaterais entre Estados do Sul, mas também no seio das instituiçōes internacionais, algo caracterizado já dentro de uma concertação multilateral. Essa concertação influiu na articulação de coalizões com propostas que contemplassem temas comuns bem como o meta-exercício de poder no exercício do diálogo com as potências do Norte (Soares de Lima, 2008).

É interessante observar que, ao fim da bipolaridade, a nova ordem internacional, embora promotora de maior distribuição de poder no mundo, também acarretou maiores constrangimentos aos países do Sul, como, por exemplo: (i) estímulos a inserção na globalização ao mesmo tempo em que restrições assimétricas ao comércio equilibrado e justo e; (ii) não contemplação das novas realidades políticas oriundas do mundo pós Guerra Fria. Constrangimentos estes que, na análise aqui espelhada, derivaram em possibilidades mais efetivas de arranjos cooperativos no eixo Sul-Sul da política internacional contemporânea.

A inserção dos três países, sob o contexto de reformas liberalizantes oriundas do "consenso" de Washington, teve um caráter híbrido no trato econômico doméstico dos países por parte dos governos brasileiro, indiano e sul-africano, mantendo ao mesmo tempo reformas econômicas para uma inserção mais competitiva na economia globalizada bem como uma postura de preservação do caráter desenvolvimentista na formulação das políticas comerciais externas da Índia, do Brasil e da África do Sul. Neste sentido, é possível dizer que o processo de liberalização econômica dos países foi mais condicionado do que, necessariamente, desatrelado às ideias desenvolvimentistas. 
De uma forma ou de outra, tanto a Índia, quanto o Brasil e a África do Sul notabilizam-se, hoje, como atores relevantes no ambiente internacional. E reconhecidos como tais pelos demais atores do ambiente internacional, formulam políticas externas visando a obter maior aproximação e convergência na diminuição da assimetria internacional. Segundo Celso Amorim, as semelhanças entre os países foram condições fundamentais para uma aproximação trilateral:

São três democracias; são três paises que têm um importante papel a desempenhar em suas respectivas regiōes; são três paises democráticos, países em que a democracia tem um forte papel na sua vida politica; são paises que têm também problemas sociais, mas que estão dispostos a enfrentá-los; e são países que têm também visões muito semelhantes em muitos temas multilaterais, e, quando não em absolutamente todos, a perspectiva que nós temos é, sem dúvida alguma, muito semelhante. Então, era preciso transformar essa coincidência virtual numa cooperação real (Brasil, 2007).

O multilateralismo Sul-Sul seria uma "saída" viável para enfrentar as adversidades sistêmicas, num momento de acentuado unilateralismo por parte da superpotência, os Estados Unidos pós-11 de Setembro, ampliando os leques de possibilidades de cooperação e parcerias, tanto nas relações diretas entre os países quanto no fortalecimento das instituiçóes internacionais.

Realmente, um dos pontos fundamentais para essa observação ocorre no âmbito das instituiçōes internacionais, observadas aqui, principalmente, em relação a ONU e a OMC, alvos institucionais de muitas das metas de política externa de seus países. Por que tanto a Índia quanto o Brasil e a África do Sul formulam, implementam e costuram suas políticas externas tanto no âmbito de relações bi ou trilaterais, mas também no âmbito das instituições internacionais, cenários elementares para a consecução de seus objetivos políticos, tenham suas políticas algum teor reivindicatório ou propositivo.

As políticas externas da Índia e do Brasil, historicamente, foram arquitetadas na busca por estratégias de inserções autônomas ao longo do século XX, conformando essas inserções num aspecto de busca por protagonismo. Protagonismo no cenário internacional no sentido de formulaçôes claras e contínuas em torno de políticas externas voltadas ao tema do não-alinhamento na Guerra Fria (embora o Brasil tenha, ao longo de sua trajetória histórica, ondulações de alinhamento irrestrito e autonomia aos Estados Unidos) e do pragmatismo assertivo (configurado em políticas de coadunação em torno de interesses setoriais, mas dentro de um quadro de multilateralismo) por isso gerando uma postura de liderança, por exemplo, no G-20, em que ambos os países lideram a coalizão e ampla concertação de interesses das potências médias.

É interessante observar, por exemplo, a percepção de que: "a Índia pertence a categoria das potências médias que aspiram a fazer a transição para categoria privilegiada das grandes potências." (Mallavarapu: 2006, 255). Caso avaliado de 
forma semelhante ao do Brasil, já que seus formuladores de política externa aspiram, de forma absolutamente consensual, transformar o Brasil em um ator relevante na política internacional. Neste sentido, é possível inferir que a aspiração tanto indiana quanto brasileira constitui parte das identidades nacionais da Índia e do Brasil.

A política externa indiana costura suas alianças e projeta seus interesses de forma a alcançar o status de grande potência no ambiente internacional. Um ponto também semelhante com o brasileiro, visto que suas elites formuladoras de política externa também projetam seus interesses e costuram alianças com esse fim. Todavia, ainda que exista um movimento por alçar os países ao status de potências globais, existe um contra-movimento que restringe essa inclusão.

Para conseguir amenizar vulnerabilidades sistêmicas, os países necessitam orquestrar, junto aos seus pares, políticas externas que se caracterizem por alinhamentos em posições temáticas conjuntamente encaradas como prioritárias para os interesses dos países no ambiente internacional. Samuel Pinheiro Guimarães (1998) aponta essas vulnerabilidades e as reparte, fundamentalmente, em três: (i) a primeira seria estabelecer programas de cooperação, tanto econômica quanto política, com seus países vizinhos; (ii) reduzir também suas vulnerabilidades econômicas externas; (iii) desenvolver sua capacidade militar, como forma de estimular a pesquisa tecnológica e adquirir conhecimentos necessários a etapas superiores de desenvolvimento.

E a África do Sul? Diferentemente da Índia e do Brasil, ela iniciou, de forma irrestrita, sua inserção internacional no contexto pós apartheid, ou seja, apenas a partir de 1990. Não que antes o país não atuasse no ambiente internacional e mesmo em relaçôes bilaterais, por exemplo, com o Brasil como assevera o estudo de Pio Penna Filho (2008). A constrangedora relação à época entre um país marcadamente miscigenado como o Brasil com um país institucionalmente segregador como a África do Sul, teve momentos de cooperação atlântica bem como momentos de afastamento e deterioração das relações.

Essa relação é retomada de forma acentuada e irrestrita (não só com o Brasil e a Índia, mas com o mundo) apenas com o processo de democratização que levou ao fim do apartheid no país. Esse cenário de relações exteriores para a África do Sul para com o Brasil não têm caráter singular, mas reflete um contexto amplo de adversidades enfrentadas pela África do Sul no ambiente internacional que apenas após o fim do apartheid são completamente exumados por sua política externa. Entretanto, é importante ressaltar que o fim do regime de apartheid não teve o caráter "mágico" de resolução de todos os problemas domésticos e de inserção internacional da África do Sul, mas ao menos minimizou os constrangimentos sistêmicos à inserção do país.

Resulta desse contexto, portanto, que indagar sobre o potencial e a construção das ambições da África do Sul são válidas, efetivamente, apenas no cenário pós apartheid (no sentido da reconfiguração da política doméstica e externa do país), destacando que foram muito mais os constrangimentos sistêmicos (rompimentos 
diplomáticos entre países, restrições ao comércio e intercâmbio cultural, fim do marco da bipolaridade sistêmica, etc.) que dificultaram a edificação das ambições internacionais sul-africanas ao longo do século XX. É interessante observar que a mudança de direção política da África do Sul já se esboçava um pouco antes do fim do apartheid na maneira como o país se reconhecia e se projetava regional e sistemicamente (prefigurando, na verdade, a insustentabilidade do nefasto regime). Ao reconhecer o país como africano e não como uma extensão da Europa na África, em 1988, o Diretor Geral do Departamento de Negócios Estrangeiros, Neil van Heerden, reflete no seu discurso a ideia que formaria e passaria a orientar a política externa sul africana:

Os problemas africanos devem ser resolvidos pelos africanos. Os interesses comuns e a responsabilidade com relação ao bem-estar econômico, sociológico e ambiental da África Austral devem ser a base da cooperação e da boa vizinhança. A África do Sul é economicamente poderosa e detém a infra-estrutura e as capacidades para ser a base do desenvolvimento regional (Mendonça: 2000, 42).

É seguro afirmar que a mudança da política externa regional sul-africana foi muito mais ambientada no seu estilo do que na sua substância, resguardando sua hegemonia regional e projetando-a dentro de uma expansão de seus interesses políticos e, principalmente, econômicos na região. Mas as aspirações por protagonismo (o regional efetivamente foi contínuo) do país no ambiente internacional desenharam-se de forma paralela, por exemplo, às da Índia e do Brasil, ressaltando, nesta avaliação presente, também um pragmatismo assertivo por parte da política externa sul-africana.

Quanto à Índia, um aspecto fundamental de análise e explicação do seu pragmatismo assertivo, por exemplo, ocorre na maneira como o país tem dimensionado sua finalidade de autonomia política concernente ao contexto de que os policy makers acreditam que o papel da Índia no sistema internacional seja muito maior que o de um país periférico (Harris: 2006, 199): "é claro que o 'clube exclusivo', no qual as elites mais aspiram ver seu país (...) é o de membros permanentes do Conselho de Segurança das Nações Unidas.” Uma aspiração também compartilhada pelos policy makers brasileiros e bem refletida nas palavras do Ministro das Relações Exteriores Celso Amorim: "o Brasil é um dos países que mais esteve presente no Conselho [de Segurança]. Temos, portanto, autoridade para apontar os problemas e os desequilíbrios que afetam o trabalho do Conselho e impõem a necessidade de mudanças" (Brasil: 2007, 197).

A ambição da África do Sul por um assento permanente no CSONU na agenda política externa do país efetuou-se de forma mais recente. Entretanto, de forma alguma significa que a inclusão no Conselho de Segurança das Nações Unidas (CSONU) não tenha aderência relevante na agenda política externa sulafricana. Muito ao contrário. Sua eleição recente como membro não-permanente 
do CSONU articula-se diretamente às suas aspiraçōes tanto no continente africano quanto no próprio ambiente internacional, já que Pretória busca trabalhar uma sinergia entre o Conselho de Paz e Segurança Africana (CPS) e o CSONU com vistas a projetar sua liderança regional na África (especialmente na África Austral) e na resolução de conflitos que consomem a região e fomentam sua instabilidade.

A importância (dentro do potencial de recursos políticos dos países), para as aspiraçōes indiana e brasileira, por um assento permanente no CSONU, é refletida na quantidade de vezes em que os países foram eleitos para os assentos não permanentes do CSONU. Como acima afirmado, embora tenha apenas um mandato ao longo de sua história, a África do Sul tem no condomínio decisório do CSONU um recurso de projeção de poder fundamental enquanto Estado Intermediário e Potência Média, algo, indubitavelmente, característico nas políticas externas da Índia e do Brasil.

\section{Tabela 1}

Perspectiva Comparada entre a Índia, o Brasil e a África do Sul em Número de Mandatos e Permanência no CSONU

\begin{tabular}{|c|c|c|c|}
\hline $\begin{array}{c}N^{\circ} \text { de } \\
\text { Ordem }\end{array}$ & Países & $\begin{array}{c}N^{\circ} \text { de } \\
\text { Mandatos }\end{array}$ & \multicolumn{1}{|c|}{ Períodos de Permanência dos Países Avaliados } \\
\hline $6^{\circ}$ & Índia & 6 & $1950-51 ; 1967-68 ; 1972-73 ; 1977-78 ; 1984-85 ; 1991-92$ \\
\hline $1^{\circ}$ & Brasil & 9 & $\begin{array}{l}1946-47 ; 1951-52 ; 1954-55 ; 1963-64 ; 1967-68 ; 1988-89 ; \\
1993-94 ; 1998-99 ; 2004-05\end{array}$ \\
\hline & África do Sul & 1 & $2006-2008$ \\
\hline
\end{tabular}

Fonte: BRASIL - Repertório de Política Externa: posiçōes do Brasil (2007)

Tanto sob a perspectiva indiana quanto brasileira e sul-africana, a aspiração pela admissão ao CSONU e a projeção de países com envergadura para a admissão ao condomínio decisório é certamente um motivo de prestígio e reconhecimento internacional. Um lugar permanente no CSONU permitiria aos países "falarem mais alto" ao exporem os seus pontos de vista acerca de propostas articuladas pelas grandes potências.

A ambição da Índia, do Brasil e da África do Sul para uma reforma institucional do CSONU (contemplando sua regionalização) busca uma efetiva transformação do status da instituição derivando, desta inferência, uma relevância maior para o desempenho dos três países no ambiente internacional. Embora deva ser ressaltado que a Índia e o Brasil têm um plano conjunto mais composto e já bem dimensionado nas suas políticas exteriores, a África do Sul tende a uma política de equilíbrio entre essa aspiração por ser membro permanente do CSONU e representante do continente africano na instituição e a aderência à proposta da União Africana, que não necessariamente a insere como a melhor alternativa à representação continental africana. 
Um ponto semelhante nas políticas assertivas multilaterais por parte da Índia e do Brasil, especialmente, é a característica de ampla articulação em torno de objetivos comuns. Suas políticas externas, ao mesmo tempo em que aspiram adquirir poder, não se efetuam como ambições políticas de curto prazo. Ao contrário, é possível observar que a Índia e o Brasil costuram alianças não apenas entre outros países desejosos de reformas institucionais nas Nações Unidas, mas também se articulando com países desenvolvidos do Norte, como a Alemanha e o Japão, formando o G-4, cujo âmbito de reivindicação concerta-se em torno de um novo desenho do CSONU especialmente dimensionado a considerar a realidade política do mundo contemporâneo. Essa articulação busca ampliar e efetivar institucionalmente uma regionalização do CSONU, garantindo, para a Índia e o Brasil, prestígio no sistema internacional, mas para isso, os policy makers indianos e brasileiros dimensionam que para sua efetivação, deve antes a instituição (no caso a ONU e o CSONU) ser prestigiada.

As percepções indiana e brasileira sofrem um ponto de vista semelhante com a perspectiva dos policy makers sul-africanos quanto a eficácia de uma concertação em torno da reforma institucional da ONU e especialmente do CSONU: sem $o$ devido prestígio das Naçôes Unidas, não há sentido em buscar um assento permanente no CSONU. E para ambos os países, num cenário unipolar e de hegemonia dos EUA, somente pelo prestígio de instituições internacionais como as Naçóes Unidas e a disposição de um novo desenho institucional do CSONU esse cenário assimétrico poderá ser minimizado.

$\mathrm{O}$ que remete à assimetria não apenas no âmbito político, mas também da interdependência econômica assimétrica. Um ponto de acentuada relevância nas aspirações das políticas externas indiana, brasileira e sul-africana é a atuação articulada entre países do mesmo status nas negociaçōes econômicas internacionais. Este processo, embora existente e importante desde a década de 1960 para a Índia e o Brasil, ganhou peso e status acentuado nas políticas externas contemporânea dos países, tendo a África do Sul alçado essa condição de concertação após o fim do apartheid. Identifica-se neste processo tanto na conjuntura sistêmica, marcada com o fim da bipolaridade da Guerra Fria e a necessidade de inserção competitiva dos países no ambiente econômico internacional globalizado, quanto na conjuntura doméstica com os pacotes de reformas macroeconômicas que visavam a dispor os países maiores condições de competitividade no comércio internacional, ainda que sob fortes e acentuadas assimetrias.

É possível inferir mesmo que o comércio internacional (dirigido pelos países desenvolvidos do Norte) restringia, efetivamente, uma participação equilibrada dos países em desenvolvimento do Sul. Neste sentido, julgo oportuno inferir que, nas negociações e nas implementações de regras multilaterais de comércio, não somente o desnível de desenvolvimento entre os países do Norte e do Sul eram percebidos, mas também entre os países do Sul em seus respectivos níveis de desenvolvimento econômico (diferenças entre, de um lado, países com economias emergentes e, 
do outro lado, países com menor desenvolvimento relativo), envolvendo, neste sentido, a exigência de tratamentos diferenciados nas negociações.

Três momentos históricos podem ser identificados nas posturas dos países em desenvolvimento nas negociações econômicas multilaterais:

1) O primeiro iria de 1947 a 1964, com participação diminuta de países em desenvolvimento devido a inexistência de tratamento diferenciado nas negociações, o que inviabilizava, efetivamente, a participação de países com economias mais frágeis;

2) O segundo iria de 1964 a 1986, com um aumento substancial da participação de países em desenvolvimento, derivando essa participação do tratamento diferenciado e;

3) Por fim, o terceiro momento, de 1986 aos dias presentes, ocorrendo negociações econômicas multilaterais concertadas entre os países em desenvolvimento ao lidar com os pleitos e reivindicações dos países desenvolvidos. $\mathrm{O}$ último momento é diretamente vinculado à concertação Sul-Sul aqui avaliada, entre a Índia, o Brasil e a África do Sul.

Neste sentido, é possível inferir que o General Agreement on Tariffs and Trade (GATT) não possuía possibilidade efetiva de sucesso para os países em desenvolvimento, já que não estava organizado e muito menos preparado para atender as demandas dos países em desenvolvimento, ou seja, por uma agenda de comércio internacional menos assimétrica e pela inclusão de status especiais aos países de economias mais frágeis e, observando-se que o GATT não se constituía em um fórum político, as reivindicações com teor político que de alguma forma pudessem vincular o comércio internacional às demandas por desenvolvimento dos países do Sul eram rapidamente excluídas.

São importantes as observaçôes sobre o desenho político do GATT por entender que o subaproveitamento das demandas dos países em desenvolvimento, em suas rodadas de negociação, foram absorvidas politicamente pelas elites políticas da Índia e do Brasil (a África do Sul, como bem se ressalta, era um outsider no ambiente internacional na maior parte deste período avaliado) e, desta forma, transformadas em recursos para a formulação e implementação de políticas externas mais pró-ativas. Os policy makers indianos e brasileiros conceberam o papel da Índia e do Brasil nas rodadas de negociação, antes postuladas no GATT e hoje na $\mathrm{OMC}$, não como países periféricos no âmbito das tomadas de decisões das rodadas, mas sim como protagonistas destas decisões.

Decisões, afinal, que afetariam as economias dos países em desenvolvimento do Sul. Assim como o Brasil, a Índia assumiu um papel de liderança do bloco de países em desenvolvimento nas negociações com os países desenvolvidos do Norte. É interessante observar que o próprio arranjo institucional da OMC permite esse quadro. Afinal, o processo decisório orquestrado na instituição preza por uma igualdade soberana, gerando, portanto, representação igualitária. Contudo, é claro, ainda que se desenhe esse cenário, os países desenvolvidos ditaram as regras de 
comércio internacional na imensa maioria das rodadas de negociação, mudando este cenário apenas após a reunião ministerial de Cancun da OMC, em 2003.

Retomando, é possível identificar o protagonismo indiano bem como brasileiro nos nove anos da Rodada Uruguai do GATT. Tanto a Índia quanto o Brasil podem ser identificados não apenas como aspirantes a protagonistas das decisões tanto no GATT quanto na OMC, mas realmente como protagonistas ao longo dos nove anos de negociações entre os países desenvolvidos do Norte e os países em desenvolvimento do Sul. Este protagonismo indiano bem como brasileiro pode também ser identificado como o exercício da liderança conjunta dos países do Sul na esfera tanto do GATT quanto da OMC.

Um exemplo possível do exercício desta liderança, podendo ser identificada como conjunta pode ser percebida na criação do G-10 com vistas ao questionamento da agenda proposta pelos Estados Unidos, cuja percepção de ameaça ao desenvolvimento dos países do Sul era percebida, originando dessa articulação o General Agreement on Trade in Services (GATS). O acordo, entretanto, "minguou" devido a consistência de posicionamento do G-10 restringindo a liberalização do setor de serviços. $\mathrm{O}$ fracasso dessa iniciativa deveu-se, em muito, ao posicionamento indiano bem como brasileiro, contrário a liberalização.

É interessante, neste sentido, observar que a Índia e o Brasil figuram na lista de principais países interpelantes e interpelados no Órgão de Soluções de Controvérsias (OSC) da OMC, entre o período de 1995-2008. Por exemplo, a Índia foi interpelada por 20 vezes no OSC, enquanto o Brasil ocupa o sexto lugar no período com 14 interpelações no OSC. Já no quesito país interpelante, a Índia acionou o OSC 18 vezes, figurando na quinta posição na lista de países interpelantes, enquanto o Brasil ocupou a quarta posição, com 24 casos. A África do Sul foi interpelada em apenas três casos desde a instituição do OSC em 1995, não ocorrendo medidas interpelantes por parte do país (WTO, 2008).

O papel acentuado de liderança dos países em desenvolvimento nas rodadas do GATT/OMC implicou no reconhecimento não apenas da potencialização econômica indiana e brasileira no ambiente econômico internacional, mas também pelo reconhecimento da assimetria não apenas entre o Norte desenvolvido e o Sul em desenvolvimento, mas também entre os próprios países do Sul. Entretanto, é válido ressaltar que as atuações indiana, brasileira e sul-africana na OMC pautaram-se pela construção de um sistema multilateral de comércio mais equitativo, mediante a correção de distorções e a diminuição das restrições às capacidades de fomentar políticas voltadas para o desenvolvimento dos países do Sul.

Por exemplo, é interessante observar que, diferentemente da Índia que prezava além da agenda econômica também a agenda de segurança, as elites dirigentes brasileiras detinham uma percepção de ameaças ao Brasil muito mais ligadas a vulnerabilidades econômicas do que de segurança propriamente. Como efeito, o teor das políticas externas indiana e brasileira deteve em suas agendas um acentuado 
caráter desenvolvimentista, sendo consideradas um recurso fundamental para a busca de desenvolvimento dos países, seja no âmbito da busca por mais cooperação econômica Sul-Sul, seja no âmbito da articulação por uma reorientação do regime de comércio internacional com os países do Norte. No caso brasileiro, as palavras do próprio Celso Amorim, Ministro das Relações Exteriores do Brasil, atestam essa articulação:

O tema do desenvolvimento tem sido historicamente um elemento central para a política externa brasileira, sobretudo no âmbito multilateral. Desde nossa contribuição pioneira à UNCTAD, estivemos presentes nos principais debates que se travaram sobre o assunto (Brasil, 2007, 12).

Ressalto que o desenvolvimento não foi o tema central apenas da política externa brasileira, mas também da política externa indiana e sul-africana. O desenvolvimento, meta perseguida pelas elites políticas indianas, brasileiras e sul-africanas (neste caso, é interessante observar a continuidade da orientação da política externa antes e depois do fim do regime de apartheid para a África do Sul), certamente orientou a percepção, formulação e implementação de suas políticas externas.

Novas percepções também passaram a configurar a formulação e implementação das políticas externas dos três países em temas que podemos identificar como estáveis, com comportamentos em negociações comerciais aderindo a um multilateralismo econômico acentuado e institucionalizado como estratégia para obtenção de maiores benefícios e ampliação do comércio internacional e emergentes, com um comportamento menos reativo em temas como o meio ambiente (mudanças climáticas), direitos humanos ou a cooperação em nível de segurança da agenda internacional. Boa parte da agenda do Sul era determinada pelos mais avançados países em desenvolvimento (Brasil e Índia entre eles). Os ganhos políticos da liderança eram maiores que os ganhos econômicos e motivavam, tanto à Índia quanto ao Brasil, a se dar conta de eventuais perdas derivadas de posicionamentos arriscados. Desta forma, a manutenção da liderança fazia parte da estratégia, ainda que ferisse, de alguma forma, os interesses nacionais.

O caso sul-africano deve realmente ser avaliado a parte. Por quê? Assim como no caso da ONU, a África do Sul sofria restrições econômico-comerciais acentuadas por parte de diversos países do Mundo (o Brasil, por exemplo, acentuou as restriçõos da década de 1970 em diante enquanto a Índia manteve uma política de restriçóes a Pretória por toda sua história independente), o que implicava negativamente no seu comércio internacional. Neste sentido, as ambiçōes sul-africanas e os interesses por um ambiente mais equilibrado registram-se também no âmbito da OMC. Julgo oportuno registrar que, para 
a África do Sul, as políticas de subsídios agrícolas da União Européia ferem diretamente os interesses sul-africanos e, neste sentido, a África do Sul não aspira apenas uma reforma da ONU, mas também da própria OMC, embora, deva ser ressaltado, sua atuação na OMC, junto ao OSC, seja bem menos ativa que a indiana e brasileira.

Neste sentido, observou-se que as políticas externas indiana, brasileira e sulafricana trabalharam com suas capacidades no efetivo exercício de obtenção de poder, não apenas no sentido clássico do realismo (a busca por prestígio, no caso), mas também na efetiva promoção de mudanças no ambiente internacional. Suas políticas externas atuaram com vistas à promoção de mudanças em ambientes institucionais internacionais, seja por meio de políticas objetivando reformas institucionais (no âmbito de aspiração) como o CSONU ou na concertação liderada de países no GATT/OMC. É importante ressaltar que a Índia e o Brasil possuem peso político muito mais denso (capacidade influente e decisória nas instituiçōes internacionais) que a África do Sul, especialmente devido a inclusão mais recente (pós apartheid) do país nas relações internacionais, e por isso é possível identificar a maior proeminência indiana e brasileira nas relaçōes internacionais contemporâneas.

Índia, Brasil e África do Sul são países de porte intermediário, mas aspiram condições (e constroem cenários para isto) de negociações equilibradas com as grandes potências. Primeiramente, é fundamental identificar que a concertação Sul-Sul dos países, objetivo alvo dessa avaliação, obedece a uma dupla incidência: $\left.1^{\circ}\right)$ uma concertação Sul-Sul com outros Estados Intermediários oferece aos três países uma maior possibilidade de parceiros comerciais, diversificando e alternando oportunidades de cooperação e ganhos econômicos e comerciais; $2^{\circ}$ ) um tipo de concertação Sul-Sul de caráter estratégico oferta aos Estados Intermediários uma possibilidade maior de interferência no contexto decisório do ambiente internacional, especialmente dimensionado nas instituiçôes internacionais.

As políticas externas de Estados do porte da Índia, do Brasil e da África do Sul são mais convergentes do que divergentes na busca por políticas que contemplem seus interesses sistêmicos. Essa convergência pode então ser operacionalizada, em vista do objetivo de indicar as características que fortalecem vínculos entre as políticas externas de países geopoliticamente eqüidistantes e com contextos econômicos também diversificados.

\section{Índia, Brasil e África do Sul: alinhamentos políticos substanciais nas instituições internacionais?}

Segundo Mônica Hirst (2006), os Estados Intermediários possuem recursos suficientes para, em conjunto, atuarem no ambiente internacional de forma próativa, afetando temas da agenda internacional. Dois pontos importantes devem 
ser ressaltados: $1^{\circ}$ ) as políticas externas da Índia, do Brasil e da África do Sul mantiveram uma trajetória em comum na obtenção de seus objetivos políticos e econômicos num eixo de cooperação Sul-Sul; $2^{\circ}$ ) ocorreu uma reformatação do modelo de coalizões Sul-Sul. O fator globalização nos faz remeter a uma diferenciação fundamental dos tipos de coalizões Sul-Sul arregimentadas entre as décadas de 1950 e 1970 do século XX e as atuais. A ideia comum de se reformar o modelo de capitalismo deu lugar ao objetivo específico de tomar parte do sistema, de também ser um país desenvolvido (ainda, ressalte-se, a busca por parte dos países em equilibrar o desenvolvimento econômico com o desenvolvimento social).

Para Nalikar e Tussie (2004), coalizões internacionais de caráter restrito a países em desenvolvimento (especialmente) possuem fragilidades que tendem a esvaziar a manutenção desses tipos de coalizões. Em especial duas características são apontadas: $1^{\circ}$ ) a capacidade econômica e política que os Estados possam ter diante de outros Estados; $2^{\circ}$ ) risco de fragmentação ou mesmo desprestígio da coalizão em virtude de conflitos de interesses entre seus membros.

Adota-se como prerrogativa analítica que as instituiçōes aprendem e desta forma os Estados podem evitar repetir erros vivenciados em outros arranjos cooperativos. Essa inferência deriva de uma reflexão oriunda também de Narlikar e Tussie (2004), na qual consideram o aprendizado como algo fundamental para que a coalizão seja eficiente, já que se leva em consideração a trajetória de articulação entre Estados, prerrogativa aderente ao se observar, por exemplo, a institucionalização do Fórum IBAS.

$\mathrm{Na}$ abordagem de Narlikar e Tussie (2004), as coalizões teriam duas características particulares: $1^{\circ}$ ) uma coalizão cujo caráter é restringido em torno de um bloco e suas fundamentaçốes mais elementares desvela em torno de questôes vinculadas às ideias ou identidades e adotam posicionamentos coletivos por meio de temas e numa trajetória; $2^{\circ}$ ) o outro modelo vincula-se a coalizões baseadas em assuntos stricto sensu, caracterizados por especificidades de caráter de racionalidade instrumental e tais coalizões surgem para enfrentar ameaças e se dispersam também rapidamente quando o tema em questão é resolvido.

Conquanto a política externa de um país venha a alimentar o desempenho da coalizão internacional que o mesmo tome parte e prestigie junto à sua agenda governamental, a ocorrência de potencialidade na formulação das políticas externas descende de interesses orientados em torno de uma agenda internacional com objetivos sumariamente semelhantes (efetivados ou não). Prescindido esse quadro de potencial (semelhante no âmbito político, econômico e de segurança, por exemplo) que os países tenham para a negociação internacional em que os mesmos venham desenvolver em alguma instituição internacional. Esse quadro se desdobra no âmbito de inferir que a convergência política entre países na seara da cooperação pode ser identificada por dois tipos de parcerias entre os Estados. 
10) Parceria Cooperativa é considerada como uma forma de relação harmoniosa quando ocorre menor grau de envolvimento entre os pares do que na parceria estratégica. Os mesmos desfrutam de relaçōes fundamentalmente positivas e produtivas em diversas áreas, entretanto, buscam desenvolver a cooperação apenas de forma limitada em questóes estratégicas e de segurança;

20) Parceria Estratégica (modelo de orientação na institucionalização da coalizão entre a Índia, o Brasil e a África do Sul) é necessário ocorrer quatro variáveis fundamentais abaixo relacionadas: (i) condução de diálogo profícuo e amistoso entre altas autoridades políticas de ambas as partes, sustentado por mecanismos institucionais; (ii) manutenção de relações dinâmicas nos campos econômicos e sociocultural, com participação de diferentes atores sociais, contribuindo para o desenvolvimento de seus projetos nacionais; (iii) desenvolvimento de cooperação ativa e abrangente em questôes estratégicas e de segurança, inclusive no campo militar; (iv) compartilhamento de visões a respeito da organização do ambiente internacional.

Nas Parcerias Estratégicas de grau mais avançado, os países envolvidos possuem interesses estratégicos e sistemas políticos semelhantes e desenvolvem relações militares estreitas, subsidiadas por serviços de informação interligados. Já as relaçôes entre aliados envolvem uma forma mais íntima e duradoura de cooperação entre nações com sistemas políticos ou econômicos semelhantes, conjugando objetivos de segurança, estabilidade e influência. Tais relações podem evoluir em direção a formação de um eixo de poder internacional, que implica não apenas em influência mútua entre os países envolvidos, mas também na ação articulada e coordenada no tratamento das mais importantes questôes internacionais.

Cabe perguntar em até que medida é possível inferir que a convergência entre os posicionamentos da Índia, do Brasil e da África do Sul refletem um alinhamento Sul-Sul nos temas mais proeminentes da agenda internacional? É importante ressaltar, primeiramente, que tanto a Índia quanto o Brasil e a África do Sul, embora tenham priorizado em suas agendas concertações Sul-Sul para melhor operacionalizarem seus interesses no ambiente internacional, não deixaram, também, de exercer autonomia em questôes que refletissem as particularidades de suas preferências, reconhecendo, mesmo, que existem diferenças entre os países, mas que as mesmas não devem ser tomadas como obstáculos à cooperação entre os mesmos.

Por exemplo, foram analisados estatisticamente pontos de convergência/ divergência nos posicionamentos entre os países do Fórum IBAS no âmbito de três regimes internacionais: segurança, direitos humanos e desenvolvimento. É válido acrescentar que o foco de observação analítica comparada entre a Índia, o Brasil e a África do Sul, não incorrendo em acréscimo de outros países para efeito de análise, deriva da possível dispersão analítica que poderia ocorrer, já que o artigo busca observar apenas a articulação institucional entre os três países. 
Mesmo após a institucionalização do Fórum IBAS, como mostrado na tabela 2, ocorreu a manutenção na tendência a maiores pontos de convergência entre os países. Mas esse processo de convergência entre os países no âmbito da ONU pode ser encarado como um processo sustentável de convergência? Ou sua configuração de alinhamento deve ser entendida como pontual ("coincidente") e não necessariamente orquestrada?

Tabela 2

Percentual de Convergência e Divergência de Posicionamentos ante Temas da Agenda da ONU

\begin{tabular}{|c|c|c|c|c|}
\hline Período & Segurança & Direitos Humanos & Desenvolvimento & Geral \\
\hline 1994 & $87,00 \%$ & $100,00 \%$ & $86,70 \%$ & $91,30 \%$ \\
1995 & $85,20 \%$ & $98,00 \%$ & $84,40 \%$ & $89,30 \%$ \\
1996 & $77,80 \%$ & $98,00 \%$ & $80,00 \%$ & $85,30 \%$ \\
1997 & $81,50 \%$ & $100,00 \%$ & $80,00 \%$ & $87,30 \%$ \\
1998 & $81,50 \%$ & $98,00 \%$ & $86,70 \%$ & $88,70 \%$ \\
1999 & $81,50 \%$ & $94,10 \%$ & $82,20 \%$ & $86,00 \%$ \\
2000 & $81,50 \%$ & $96,10 \%$ & $91,10 \%$ & $89,30 \%$ \\
2001 & $85,20 \%$ & $90,20 \%$ & $86,70 \%$ & $87,30 \%$ \\
2002 & $83,30 \%$ & $98,00 \%$ & $93,30 \%$ & $91,30 \%$ \\
2003 & $83,30 \%$ & $92,20 \%$ & $93,30 \%$ & $89,30 \%$ \\
2004 & $85,20 \%$ & $90,20 \%$ & $91,10 \%$ & $88,70 \%$ \\
Média de Convergência & $83,00 \%$ & $95,90 \%$ & $86,90 \%$ & $88,50 \%$ \\
\hline
\end{tabular}

Fonte: UNDATA (2008)

O resultado obtido por meio dos dados, considerando os onze anos dispostos no recorte temporal e todas as votaçôes envolvidas em torno de três grandes regimes: (i) segurança, (ii) direitos humanos e (iii) desenvolvimento demonstra uma alta incidência de convergência (no âmbito das votaçôes na Assembléia Geral das Nações Unidas) de posicionamentos entre os países, 88,50\% de convergência de posicionamentos. É possível inferir uma dupla incidência de autonomia em posicionamentos ao mesmo tempo em que alinhamentos estratégicos nas posições tomadas ante os regimes internacionais. ${ }^{1}$

1 Os temas votados na Assembléia Geral das Nações Unidas (AGNU) ao longo do recorte de tempo foram: ciência e tecnologia; risco de proliferação nuclear no oriente médio; proibição de minas terrestres; armas convencionais no nível regional; transparência em armamentos; Hemisfério Sul sem armas nucleares; Por uma agenda sem armas nucleares; eliminação total das armas nucleares; desarmamento nuclear; desarmamento nuclear e extinção de armas nucleares; armas químicas e biológicas; banimento de testes nucleares; Oriente Médio desnuclearizado; Sul Asiático desnuclearizado; América Latina desnuclearizada; África desnuclearizada; TNP; Proibição do uso de armas nucleares; comércio internacional e desenvolvimento; Direito ao Desenvolvimento; Direitos da Criança; Globalização e Direitos Humanos; Direitos Humanos e 
Feita essa observação em relação às atividades e alinhamento conjunto dos três países no âmbito da ONU, julgo importante voltar a observação ao espectro da OMC. Considero fundamental discorrer brevemente sobre o G-20 com o fim de observar uma coalizão não formal que tanto Índia quanto Brasil e África do Sul tomam parte. Surgido na conferência da OMC em Cancun, outra concertação entre países do Sul, com presença da Índia, do Brasil, da China, da África do Sul, da Argentina etc, e especialmente liderado pelos três primeiros países nas rodadas de negociação da OMC. O G-20 caracteriza-se por ser uma coalizão setorial, focado fundamentalmente no tema da agricultura, objetivo central da Agenda de Desenvolvimento de Doha. É interessante observar que, no caso do G-20, os países em desenvolvimento conseguiram, graças ao seu arranjo de concertação, impor um novo papel (protagonístico) no âmbito das negociações sobre liberalização do comércio internacional. Esse peso reflete nos números que representam os países de três continentes: $60 \%$ da população rural do planeta, $12 \%$ da produção agrícola, $26 \%$ das exportações e 18\% das importaçôes mundiais (Oliveira, 2005).

O Brasil e a Índia, embora exerçam liderança no âmbito da OMC, possuem comportamentos diferenciados devido a interesses diferenciados no que tange a abertura de seus respectivos mercados domésticos. Enquanto a Índia mantém uma postura mais defensiva e protecionista para bens agrícolas, o Brasil destacase por um comportamento mais flexível à possibilidade de abertura comercial, promovendo, nas rodadas de negociação, comportamentos mais demandantes e dispostos às negociaçóes com os países do Norte de forma a barganhar melhores condições de competitividade comercial. No caso, Índia e Brasil estreitam uma cooperação desde antes de se alinharem também à África do Sul, já que o país africano esteve, como já foi ressaltado, passível de restrições à sua atuação no ambiente internacional com o regime do apartheid.

A cooperação existente entre os três países também não se caracteriza por uma questão específica, já que os três países são parceiros, também, no G-20 e no Fórum Trilateral de Diálogo IBAS, o que indica a existência de interesses e demandas em comum para os países. É interessante observar, também, que num cenário de interdependência econômica assimétrica tanto para a Índia quanto para o Brasil e a África do Sul a atuação de forma multilateral com outros países, na esfera da OMC, tende a gerar benefícios maiores do que uma atuação unilateral (Keohane, 1992, p. 165). Essa inferência pode ser disposta como suporte analítico ao se observar as coalizóes que cada país toma parte no âmbito da OMC como visualizados na tabela 3 .

Terrorismo; Direitos Humanos e Medidas Coercitivas Unilaterais; Distribuição equânime em Tratados de Direitos Humanos; Direito à Auto-Determinação; Liberdade de Viagem e Reunificação Familiar; Execuçôes Sumárias; Mercenários; Respeito aos Princípios da Carta da ONU; ONU e Democracia; Ordem Internacional Democrática; Intolerância Religiosa; Eliminação do Racismo, Xenofobia e Intolerância; Acesso à Medicamentos (UNDATA, 2008). Os temas foram, portanto, dimensionados dentro dos regimes internacionais de segurança, desenvolvimento e direitos humanos para melhor alocação analítica do trabalho. 
Tabela 3

Concertações que Índia, Brasil e África do Sul tomam parte no âmbito GATT/ OMC

\begin{tabular}{|c|c|c|c|c|}
\hline $\begin{array}{l}\text { Coalizões que } \\
\text { ao menos dois } \\
\text { dos países do } \\
\text { IBAS tomam } \\
\text { parte }\end{array}$ & Classificação & Países & $\begin{array}{l}\text { Status dos } \\
\text { Países }\end{array}$ & Objetivos \\
\hline G-10 & Bloco & $\begin{array}{l}\text { Argentina, Brasil, } \\
\text { Cuba, Egito, Índia, } \\
\text { ex-lugoslávia, } \\
\text { Nicarágua, Nigéria, } \\
\text { Peru, Tanzânia. }\end{array}$ & $\begin{array}{l}\text { Países em } \\
\text { Desenvolvimento }\end{array}$ & $\begin{array}{l}\text { A coalizão tinha } \\
\text { por objetivo } \\
\text { inicial bloquear o } \\
\text { começo de uma } \\
\text { nova rodada e } \\
\text { barrar a inclusão } \\
\text { de serviços no } \\
\text { GATT. }\end{array}$ \\
\hline G-20 & Temática & $\begin{array}{l}\text { África do Sul, } \\
\text { Argentina, Bolívia, } \\
\text { Brasil, Chile, China, } \\
\text { Cuba, Egito, } \\
\text { Filipinas, Guatemala, } \\
\text { Índia, Indonésia, } \\
\text { México, Nigéria, } \\
\text { Paquistão, Paraguai, } \\
\text { Tailândia, Tanzânia, } \\
\text { Uruguai, Venezuela, } \\
\text { Zimbábue. }\end{array}$ & $\begin{array}{l}\text { Países em } \\
\text { Desenvolvimento }\end{array}$ & $\begin{array}{l}\text { Liberalização } \\
\text { do Comércio } \\
\text { Agrícola. }\end{array}$ \\
\hline Cairns Group & Temática & $\begin{array}{l}\text { África do Sul, } \\
\text { Argentina, Austrália, } \\
\text { Bolívia, Brasil, } \\
\text { Canadá, Chile, } \\
\text { Colômbia, Costa Rica, } \\
\text { Filipinas, Guatemala, } \\
\text { Indonésia, Malásia, } \\
\text { Nova Zelândia, } \\
\text { Paraguai, Tailândia, } \\
\text { Uruguai. }\end{array}$ & $\begin{array}{l}\text { Países em } \\
\text { Desenvolvimento } \\
\text { e Países } \\
\text { Desenvolvidos }\end{array}$ & $\begin{array}{l}\text { Inclusão da } \\
\text { Agricultura } \\
\text { no âmbito do } \\
\text { GATT e posterior } \\
\text { liberalização } \\
\text { do comércio } \\
\text { agrícola. }\end{array}$ \\
\hline $\begin{array}{l}\text { G-24 sobre } \\
\text { Serviços }\end{array}$ & Temática & $\begin{array}{l}\text { Argentina, Bolívia, } \\
\text { Brasil, Colômbia, } \\
\text { Cuba, El Salvador, } \\
\text { Equador, Filipinas, } \\
\text { Honduras, } \\
\text { Índia, Indonésia, } \\
\text { Malásia, México, } \\
\text { Nicarágua, Panamá, } \\
\text { Paquistão, Paraguai, } \\
\text { Peru, República } \\
\text { Dominicana, Sri } \\
\text { Lanka, Tailândia, } \\
\text { Uruguai, Venezuela. }\end{array}$ & $\begin{array}{l}\text { Países em } \\
\text { Desenvolvimento }\end{array}$ & $\begin{array}{l}\text { Sugestões sobre } \\
\text { as negociações } \\
\text { sobre serviços e } \\
\text { propostas para } \\
\text { obtenção de } \\
\text { créditos quando } \\
\text { um país abre } \\
\text { sua economia de } \\
\text { forma autônoma. }\end{array}$ \\
\hline
\end{tabular}

Fonte: elaborado pelo autor a partir de Paulo \& Onuki (2007) 
Políticas externas de caráter multilateral são comuns aos três países. E as rodadas de negociação no âmbito da OMC são percebidas como cenários ideais para a ampliação dos benefícios possíveis com a articulação multilateral de interesses dos países em desenvolvimento. Tanto Índia quanto Brasil e África do Sul, ao longo de suas trajetórias de negociação tanto no GATT quanto na própria OMC, atuam de maneira assertiva em torno de coalizóes em bloco ou temáticas. A Índia participa de 09 coalizões, enquanto o Brasil e a África do Sul participam de cinco e quatro coalizões, respectivamente, sendo que as coalizôes em que os três países participam são majoritariamente temáticas, com objetivos específicos de reivindicação e proposição.

Também é possível observar que o Brasil encontra-se em coalizões tanto com a Índia quanto com a África do Sul, mas não ocorre com a África do Sul encontrar-se numa coalizão com a Índia sem a participação brasileira. Por exemplo, é possível observar que outros Estados mantêm coalizões regulares na OMC com o Brasil, como a participação argentina, tradicional parceira brasileira, em todas as coalizões (quatro ao total) que algum país do Fórum IBAS tome parte. Contudo, analisar a convergência entre do Brasil com a Índia (principalmente) e com a África do Sul não remete que Brasília tenha mais convergência com New Delhi ou Pretoria do que com Buenos Aires, mas sim que no tipo de coalizão desenhada apenas entre Índia, Brasil e África do Sul não configura relevância a inclusão dessa variável para mensurar o grau de convergência indiana, brasileira e sul-africana em temas do comércio internacional. De qualquer forma, para a Índia, o Brasil e a África do Sul ocorre em suas trajetórias uma manutenção de políticas multilaterais no âmbito da $\mathrm{OMC}$ e, como consequiência, a participação acentuada em diversas coalizões refletiu no arranjo e sustentabilidade da concertação entre os três Estados Intermediários.

É oportuno ressaltar uma característica das relações trilaterais entre: a) Brasil e Índia; b) África do Sul e Brasil; c) Índia e África do Sul. As relaçôes entre Brasil e Índia bem como entre África do Sul e Brasil, e Índia e África do Sul são de baixa complementaridade bilateral (refletida nas baixas relações comerciais e estratégias políticas conjuntas quando tomadas em uma longa trajetória), enquanto nas relaçôes Sul-Sul, por parte da Índia, do Brasil tanto quanto da África do Sul, a baixa complementaridade bilateral de relaçóes entre os países, por exemplo, é amenizada pela alta complementaridade multilateral (ONU, OMC). Neste sentido, tanto um aspecto quanto outro influem no desempenho da coalizão IBAS.

Embora sejam competidores em vários produtos e serviços nos mercados mundiais, acrescentando, ainda, que o comércio entre os países seja dificultado pelas distâncias (o que gera em parte a baixa complementaridade bilateral), os governos da Índia, do Brasil e da África do Sul ambicionam redimensionar suas relaçôes, seja no âmbito comercial, seja no âmbito de cooperação técnica, por exemplo. Um ótimo aspecto para se observar esse quadro (baixa complementaridade 
bilateral) pode ser encontrado no âmbito do comércio entre os países. O comércio entre a India, o Brasil e a África do Sul equivale a apenas $2 \%$ da soma do intercâmbio entre os três paises.

Tanto o comércio entre a Índia, o Brasil e a África do Sul quanto com seus respectivos blocos de integração econômica aumentaram significativamente (e especialmente após a institucionalização do Fórum IBAS). O intercâmbio entre Índia e Mercosul mais do que duplicou entre 2001 e 2005, passando de menos de US \$ 1 bilhão para US \$2,3 bilhões. Além disso, o fluxo comercial entre a Índia e a África do Sul aumentou 133\% no mesmo período, subindo de US\$1,3 bilhão para US\$ 3,1 bilhões.

Observa-se que os Chanceleres da Índia, do Brasil e da África do Sul possuem um otimismo político quanto ao aumento do comércio trilateral entre os países bem como a superação dos obstáculos existentes. Para Celso Amorim: "Acreditamos que em poucos anos atingiremos de US \$ 14 bilhões a US $\$ 15$ bilhões nesse tríplice comércio. Atualmente, os acordo bilaterais entre Brasil e Índia e Brasil e África do Sul, já rendem US \$ 4 bilhões. Então, chegar aos US\$ 15 bilhões não é um projeto tão difícil de concretizar." Perspectiva acrescentada por Nkosazana Zuma, Chanceler da África do Sul em 2006: "Não adianta avançarmos nas relações comerciais se não houver logística para amparar este intercâmbio. Se não tivermos transportes, o comércio entre os países será afetado. Por isso, nos próximos meses os grupos de trabalho nessa área vão fazer um esforço dobrado para evoluir no que diz respeito a transporte aéreo e marítimo" (Gazeta Mercantil, 2006).

A divisão entre baixa complementaridade bilateral e alta complementaridade multilateral denota uma rota política que fundamenta uma aproximação multilateral entre os países e permite visualizar uma inferência positiva na construção de arranjos de interesses mútuos, como a formulação de uma agenda IBAS, ou seja, embora existam paralelamente (baixa complementaridade bilateral $\mathrm{X}$ alta complementaridade multilateral), a primeira é tomada como incentivo para $\mathrm{o}$ incremento das relações (bilaterais ou trilaterais) caracterizando a percepção de oportunidade, enquanto a segunda reflete a absorção da oportunidade pelos países e na operacionalização de seus interesses em políticas de caráter multilateral.

\section{Considerações Finais}

O desenho da concertação entre os três Estados Intermediários obedece a um arranjo de cooperação amplo (diversos interesses e objetivos), com uma agenda em comum setorizada cujos efeitos são desdobrados pelas políticas externas (assertivas e protagonísticas) da Índia, do Brasil e da África do Sul, cujo maior desdobramento foi a institucionalização do Fórum de Diálogo Trilateral IBAS. Como efeito, a concertação entre Índia, Brasil e África do Sul, como arranjo de interesses derivado das políticas externas indiana, brasileira e sul-africana e sob 
efeito dos constrangimentos sistêmicos, é marcada por configurar-se como uma cooperação entre Estados fundamentalmente ambiciosa (do ponto de vista sistêmico cujas políticas são de reconfiguração e re-equilíbrio de poder entre as naçōes) e pontual (do ponto de vista da articulação comercial trilateral ou no âmbito da cooperação técnica). Esse quadro gera, do ponto de vista de eficácia, de certa forma uma tensão entre os objetivos da coalizão (Lima, 2005).

Ainda que ocorram críticas ao caráter de concertação estratégica entre os três países, é possível observar que as complementaridades são mais aderentes às políticas multilaterais da Índia, do Brasil e da África do Sul do que os fatores competitivos. Indubitavelmente, o próprio Fórum IBAS carece de conhecimento público nos três países, ainda que iniciativas já estejam sendo feitas para minimizar esse quadro deficitário, seja por iniciativas de câmaras comerciais interessadas em estreitar laços comerciais ou no fomento de ações parlamentares trilaterais. Justamente por ser uma iniciativa de caráter político, a concertação entre três países do Sul foi constituída por aspirações em comum, positivamente orientadas em torno de um mesmo eixo de preferências conduzindo suas políticas externas, essas aspirações em comum fomentaram os esforços por sistematizar uma concertação política. Esforços estes que se desdobraram em consultas políticas de forma contínua ao longo dos anos transcorridos e na maior exploração de políticas tanto multilaterais quanto trilaterais, até mesmo para amenizar a baixa complementaridade bilateral entre os países.

Em relação aos alvos institucionais internacionais, a coalizão tem um desempenho eficiente em cenários onde é possível maior dispersão de poder decisório (como a OMC) enquanto cenários mais concentradores de poder decisório (CSONU) o desempenho político da coalizão é ineficiente no tocante aos seus objetivos de agenda, observando-se que o comportamento das políticas externas da Índia, do Brasil e da África do Sul mantém um mesmo padrão de atuação (perseguição de seus objetivos que podem conflitar ou não com seus parceiros em alguns pontos) tanto no âmbito da ONU quanto da OMC. Desta forma, o objetivo original da concertação entre os três países, a reforma do CSONU, encontra-se muito mais próximo de forte retórica do que necessariamente do sucesso no objetivo.

O Fórum IBAS "veio para ficar", afirmou o Presidente Lula da Silva (Moura: 2008, p. 34). É uma consideração realmente válida, mas, retóricas a parte, o desempenho político da coalizão Sul-Sul, como uma concertação sui generis entre países em desenvolvimento de três continentes diferentes, reflete a própria ambição de seus participantes. Os objetivos da concertação política entre a Índia, o Brasil e a África do Sul são diversos (por isso uma agenda que contempla diversos temas) e por serem diversos o desempenho político da coalizão também é diversificado, seja para uma eficiência maior, menor ou inexistente. 


\section{Referências bibliográficas}

AFRICAN NATIONAL CONGRESS. Foreign Policy in a New Democratic South Africa. A Discussion Paper (1993). Publicado em: http://www.anc.org.za/andocs/history/transition. Disponibilidade: 12/10/ 2008.

BRASIL. Repertório de Política Externa: posições do Brasil. Brasília: FUNAG, 2007.

GAZETA MERCANTIL. Brasil define metas com Índia e África do Sul, 2006.

HIRST, Monica. "Intermediate States, Multilateralism \& International Security." In: VAZ, Alcides. Costa (Org.). Intermediate States, regional leadership and security: India, Brazil and South Africa. Brasília: Editora Universidade de Brasília, 2006. p. 165-194.

HARRIS, John. "Os amargos frutos da ambição grandiosa." In: VIZENTINI, Paulo Fagundes; WIESEBRON, Marianne. (Org.). Neohegemonia americana ou multipolaridade? Pólos de poder e sistema internacional. Porto Alegre: Editora da UFRGS, 2006. p. 198-211.

KEOHANE, Robert. "International Institutions: can interdependence work?” In: ART, R. J.; JERVIS, Robert. (Org.). International Politics: enduring concepts and contemporary issues. Nova York: Pearson Education, Inc, 2005. p. 119-136.

KUMAR, Satish. “Índia e Brasil no Cenário Político Internacional da Próxima Década.” In: GUIMARÃES, Samuel Pinheiro. (Org.). Estratégias Índia e Brasil. Brasília: IPRI e Fundação Alexandre de Gusmão, 1997. p. 167-172.

MALLAVARAPU, Siddharht. "O modelo de globalização e a formulação da política externa indiana.” In: VILLARES, Fábio. (Org.). India, Brasil e África do Sul: perspectivas e alianças. São Paulo: Editora Unesp: IEEI, 2006. p. 213-274.

MENDONÇA, Hélio. "Política Externa da África do Sul (1945-1999). In: GUIMARĀES, Samuel Pinheiro. (Org.). África do Sul: visões brasileiras. Brasília/São Paulo: IPRI/FUNAG, 2000. p. 11-100.

MOURA, Gilberto Fonseca. "O Diálogo Índia, Brasil, África do Sul - IBAS: Balanço e Perspectivas.” In: Seminário IBAS: textos acadêmicos. Brasília: FUNAG, 2008. p.13-40.

NARLIKAR, Amrita. International Trade and Developing Countries: bargaining coalitions in the GATT \& WTO. London: Routledge, 2003.

NARLIKAR, Amrita. \& TUSSIE, D. Bargaining Together in Cancun: Developing Countries and Their Evolving Coalitions. mimeo, Exter, UK e Buenos Aires, 2004.

OLIVEIRA, Marcelo Fernandes. "Estratégias internacionais e diálogo Sul-Sul no governo Lula: alianças duradouras ou coalizões efêmeras?” In: VILLARES, Fábio. (Org.). Índia, Brasil e Africa do Sul: perspectivas e alianças. São Paulo: Editora Unesp: IEEI, 2006. p. 313-334.

"Alianças e coalizōes internacionais do governo Lula: o Ibas e o G-20.” Revista Brasileira de Politica Internacional. Vol.8, No 2, 2005, p. 55-69.

OLIVEIRA, Amancio Jorge Nunes de; ONUKI, Janina; OLIVEIRA, Emmanuel. "Coalizões Sul-Sul e Multilateralismo: Índia, Brasil e África do Sul.” Contexto Internacional. Vol. 28, No 2, 2006, p. 465-504.

PAULO, Cinthia Konishi; ONUKI, Janina. "Coalizões Sul-Sul: mapeamento, tipologia e estratégias." In: OLIVEIRA, Amancio. ONUKI, Janina. (Org.). Coalizôes Sul-Sul e as Negociaçôes Multilaterais: os países intermediários e a coalizão IBSA. São Paulo: Mídia Alternativa Comunicação e Editora, 2007. p. 103-152. 
PENNA FILHO, Pio. O Brasil e a África do Sul: o arco atlântico da política externa brasileira (1918-2000). Porto Alegre: FUNAG/MRE, 2008.

SARAIVA, Miriam Gomes. "As estratégias de cooperação Sul-Sul nos marcos da política externa brasileira de 1993 a 2007." Revista Brasileira de Politica Internacional. Vol. 50, No 2, 2007, p.42-59.

SOARES DE LIMA, Maria Regina. "A Política externa brasileira e os desafios da cooperação sul-sul”. Revista Brasileira de Politica Internacional. Brasília: Vol. 48, No 1, 2005, p. 24-59.

VIOLA, Eduardo; PIO, Carlos. "Doutrinarismo e Realismo na Percepção do Interesse Nacional: Política Macroeconômica, Segurança e ALCA na relação Brasil - Estados Unidos”. In: OLIVEIRA, M.G. (Org.). Brasil e EUA no novo milênio. Recife: NEA/Ed.Universitária da UFPE, 2003. p. 13-42

UNDATA. (2008), Publicado em: www.data.un.org. Disponibilidade em 12 de Dezembro de 2008.

WTO. (2008), Disputas por Países. Publicado em www.wto.org/english/tratop_e/dispu_e/ dispu_by_country_e.htm>. Disponibilidade em: 05 de Janeiro de 2008.

Recebido em 20 de abril de 2009 Aprovado em 10 de julho de 2009

\section{Resumo}

Este trabalho busca examinar o desempenho político da concertação internacional entre a Índia, o Brasil e a África do Sul a partir do comportamento das políticas externas dos países concertados. A hipótese é de que o desempenho político eficiente de uma concertação internacional entre Estados Intermediários depende de políticas externas assertivas e alinhadas na busca por atingir as preferências (metas institucionais) de sua concertação, dimensionadas aqui para avaliação no âmbito de instituiçõos internacionais como a Organização das Nações Unidas e a Organização Mundial do Comércio.

\section{Abstract}

This research seeks to examine the policy performance of international concertation of India, Brazil and South Africa based on the behavior of the countries' foreign policies related. The hypothesis is that an efficient political performance between Intermediate States depends on external political assertions and aligned in the search for achieving the preferences (institutional goals) of their agreement, designed here for evaluation as part of international institutions like the United Nations and the World Trade Organization.

Palavras-chave: Coalizões Internacionais Sul-Sul; Política Externa Comparada; Estados Intermediários.

Key-words: South South International Coalitions; Comparative Foreign Policy; Intermediate States. 